\title{
Challenges of soil carbon sequestration in the NENA region
}

\author{
Talal Darwish ${ }^{1,3}$, Thérèse Atallah ${ }^{2}$, and Ali Fadel ${ }^{1}$ \\ ${ }^{1}$ National Council for Scientific Research, Beirut, Lebanon \\ ${ }^{2}$ Faculty of Agricultural and Veterinary Sciences, Lebanese University, Dekwaneh, Lebanon \\ ${ }^{3}$ Intergovernmental Technical Panel on Soil (ITPS), Global Soil Partnership (GSP), FAO, Rome, Italy \\ Correspondence: Talal Darwish (tdarwich@cnrs.edu.lb)
}

\author{
Received: 15 December 2017 - Discussion started: 12 January 2018 \\ Revised: 3 August 2018 - Accepted: 9 September 2018 - Published: 26 September 2018
}

\begin{abstract}
The Near East North Africa (NENA) region spans over $14 \%$ of the total surface of the Earth and hosts $10 \%$ of its population. Soils of the NENA region are mostly highly vulnerable to degradation, and future food security will much depend on sustainable agricultural measures. Weather variability, drought and depleting vegetation are dominant causes of the decline in soil organic carbon (SOC). In this work the status of SOC was studied, using a land capability model and soil mapping. The land capability model showed that most NENA countries and territories (17 out of 20) suffer from low productive lands ( $>80 \%)$. Stocks of SOC were mapped $(1: 5000000)$ in topsoils $(0-0.30 \mathrm{~m})$ and subsoils $(0.30-1 \mathrm{~m})$. The maps showed that $69 \%$ of soil resources are shown to have a stock of SOC below the threshold of 30 tons ha $^{-1}$. The stocks varied between $\approx 10$ tons ha $^{-1}$ in shrublands and 60 tons ha ${ }^{-1}$ for evergreen forests. Highest stocks were found in forests, irrigated crops, mixed orchards and saline flooded vegetation. The stocks of soil inorganic carbon (SIC) were higher than those of SOC. In subsoils, the SIC ranged between 25 and 450 tons ha $^{-1}$, against 20 to 45 tons ha $^{-1}$ for SOC. Results highlight the contribution of the NENA region to global SOC stock in the topsoil (4.1\%). The paper also discusses agricultural practices that are favorable to carbon sequestration such as organic amendment, no till or minimum tillage, crop rotation and mulching and the constraints caused by geomorphological and climatic conditions. The effects of crop rotations on SOC are related to the amounts of above and belowground biomass produced and retained in the system. Some knowledge gaps exist, especially in aspects related to the impact of climate change and effect of irrigation on SOC, and on SIC at the level of the soil profile and soil landscape. Still, major constraints facing soil carbon sequestration are policy-relevant and socioeconomic in nature, rather than scientific.
\end{abstract}

\section{Introduction}

The Near East North Africa (NENA) region spans over $14 \%$ of the total surface of the Earth and hosts $10 \%$ of its population (Elhadi, 2005). The largest importer of wheat in the world, this region is also one of the poorest (FAO, 2015). A recent assessment of global hunger index (GHI), based on four indicators - undernourishment, child wasting, child stunting and child mortality - showed that most of the NENA countries and territories reflect a low to moderate GHI. Countries suffering from armed conflicts, Syria, Iraq and Yemen, are at a serious risk (von Grebmer et al., 2017). With the scarce natural resources and difficult socioeconomic condi- tions, it is questionable whether food security will be reached by 2030, unless a significant change in agricultural practices and governance occurs (FAO, 2017).

Most of the land area of the NENA region falls in the hyper-arid, arid and semi-arid climatic zones. Climate change is expected to exacerbate drought and the scarcity of water. Weather variability, drought and depleting vegetation are major concerns in the loss of soil productivity and agricultural sustainability. Changes in soil organic carbon (SOC) can affect the emission of greenhouse gases to the atmosphere and negatively influence the global climate (Lal, 2003). In fact, destructive land management practices are im- 
pacting soil functions. Land use change, mono-cropping and frequent tillage are considered to cause a rapid loss of SOC (Guo et al., 2016). These agricultural practices disturb the stability of soil characteristics, employed under local land cover (LC) and climate conditions (Bhogal et al. 2008). Thus, most NENA lands contain $\sim 1 \%$ of SOC, and frequently less than $0.5 \%$.

NENA pedo-climatic conditions present major constraints on carbon sequestration (Atallah et al., 2015). To maintain soil productivity and land quality, several technical and socioeconomic measures need to be adopted. Additional efforts oriented to maintaining and increasing SOC can contribute to poverty reduction and achieve food security (Plaza-Bonilla et al., 2015). Good agricultural practices, based on low tillage or no tillage, may result in the reduction of SOC breakdown and the enhancement of the soil carbon pool (Atallah et al., 2012; Cerdá et al., 2012; Boukhoudoud et al., 2016).

In order to compare situations and problems, global soil organic carbon maps are a priority. As recently as December 2017, the GSP-FAO ITPS launched version 1 of the global soil organic carbon map, showing the SOC stock in topsoil (http://www.fao.org/3/a-i8195e.pdf; last access: 19 August 2018). A preliminary assessment of regional SOC stocks, using unified background information, is needed to analyze the challenges facing $\mathrm{C}$ sequestration. Maps of the spatial distributions of organic carbon (OC) stocks can be used to monitor regional and global $\mathrm{C}$ cycles. Accurately quantifying SOC stocks in soils and monitoring their changes are essential to assessing the state of land degradation. At the same time, the predominantly calcareous soils of the NENA region are rich in soil inorganic carbon (SIC). The dynamics of SIC and its potential in sequestrating soil carbon are largely unknown and deserve thorough investigation. This paper analyzes the state of SOC and SIC in NENA countries and territories and outlines challenges and barriers for devising organic carbon sequestration in NENA's impoverished and depleted soils. It also highlights several questions which scientists need to resolve. Finally, it discusses practical agricultural measures to promote SOC sequestration.

\section{Materials and methods}

Data on SOC and soil inorganic carbon (SIC) contents in soils were retrieved from the soil database of the FAOUNESCO Digital Soil Map of the World (DSMW) at 1 : 5000000 . Within the database, 1700 geo-referenced soil profiles, collected from all member states of the NENA region, are included (FAO, 2007).

In terms of area, the largest soil units are Yermasols $\left(4670.6 \mathrm{~km}^{2}\right)$, Lithosols $\left(2914.3 \mathrm{~km}^{2}\right)$ and Regosols $\left(1193.2 \mathrm{~km}^{2}\right)$. The great majority of soil classes have very low to low resistance to erosion and degradation (Table 1). Conversely, Cambisols, Fluvisols and Regosols are highly resistant to erosion. Soil classes dominated by calcareous rocks
(Solonchaks, Rendzinas and Aridisols) have the highest SIC content (Table 1), while Lithosols and Xerosols, subject to regular water and wind erosion, show the smallest SIC.

The SOC content can vary depending on soil type, topography, land cover, erosion-sedimentation and soil management. Within the topsoil $(0-0.30 \mathrm{~m})$, the SOC contents are between $0.13 \%$ and $1.74 \%$, while in the subsoil $(0.30-1 \mathrm{~m})$ values range between $0.16 \%$ and $0.9 \%$ (Fig. 1). Two out of the three predominant soil classes (Xerosols and Aridisols) have SOC contents below $0.5 \%$. Overall, the NENA soils are poor in SOC, as less than $20 \%$ of soil resources have SOC contents above $1.0 \%$.

The NENA soil map was prepared using the topographic map series of the American Geographical Society of New York, as a base, at a nominal scale of 1:5000000. Country/territory boundaries were checked and adjusted using the FAO-UNESCO Soil Map of the World. Soil classification was based on horizon designation, depth, texture, slope and soil physicochemical properties. Main agricultural soil properties were assessed using the statistical (weighted) average in the topsoil and subsoil. For the production of the maps of $\mathrm{C}$ stocks and distribution (FAO, 2007), ArcMap 10.3 was used to join the geometric database with the $\mathrm{C}$ stocks. These were ranked into five categories for SOC density $(0-14,14-$ 22, 22-31, 31-61 and 61-236 tons ha ${ }^{-1}$ ) and five others for SIC (0, 0.1-30, 30-45, 46-74 and 74-200 tons ha $\left.{ }^{-1}\right)$.

The land cover map was that of the European Space Agency (ESA), at $300 \mathrm{~m}$ spatial resolution. The reference coordinate system used was a geographic coordinate system based on the World Geodetic System 84 (WGS84) reference ellipsoid. The legend assigned to the global LC map was based on the UN Land Cover Classification System.

Total SOC and SIC stocks were calculated separately for the topsoil $(0-0.3 \mathrm{~m})$ and subsoil $(0.3-1.0 \mathrm{~m})$ using the following equations:

$$
\begin{aligned}
& \text { national C stock (ton) }=\left[\text { area }\left(\mathrm{m}^{2}\right) \times \operatorname{depth}(\mathrm{m})\right. \\
& \left.\times \text { bulk density }\left(\text { ton } \mathrm{m}^{3}\right) \times \text { OC content }(\%)\right] / 100 \\
& \text { SOC or SIC density (ton ha } \left.{ }^{-1}\right)=\text { stock in given } \\
& \text { soil unit (ton)/soil unit area (ha). }
\end{aligned}
$$

Stocks of SOC under different land cover/land use were evaluated as well. Since 1990, the ESA (Climate Change Initiative project) has started to produce LC maps of the NENA region. The version used in the study corresponds to the second phase of the 2015 global LC (http://maps.elie.ucl.ac.be/ CCI/viewer/index.php; last access: 10 September 2017) with a spatial resolution of $300 \mathrm{~m}$. 
(a) $\quad \%$ soc topsoil

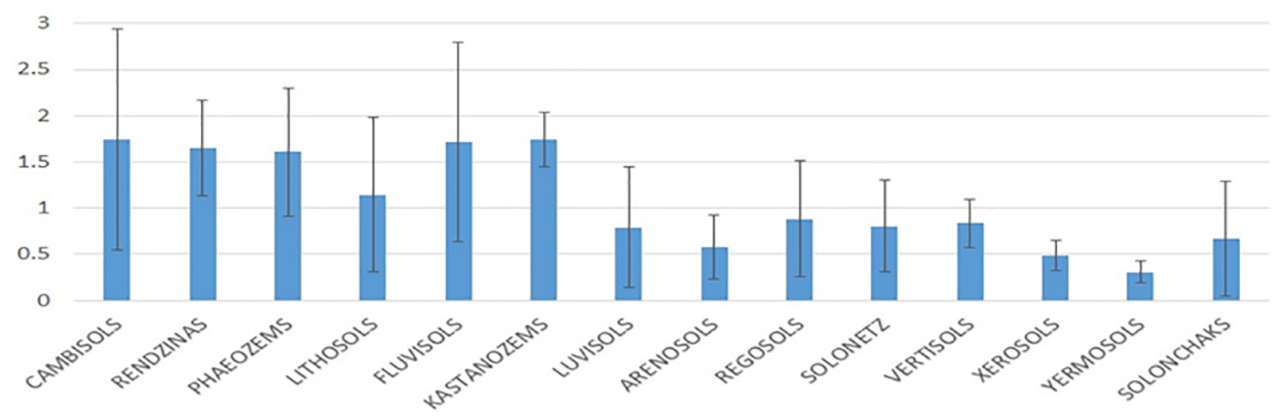

(b)

$\%$ SOC subsoil
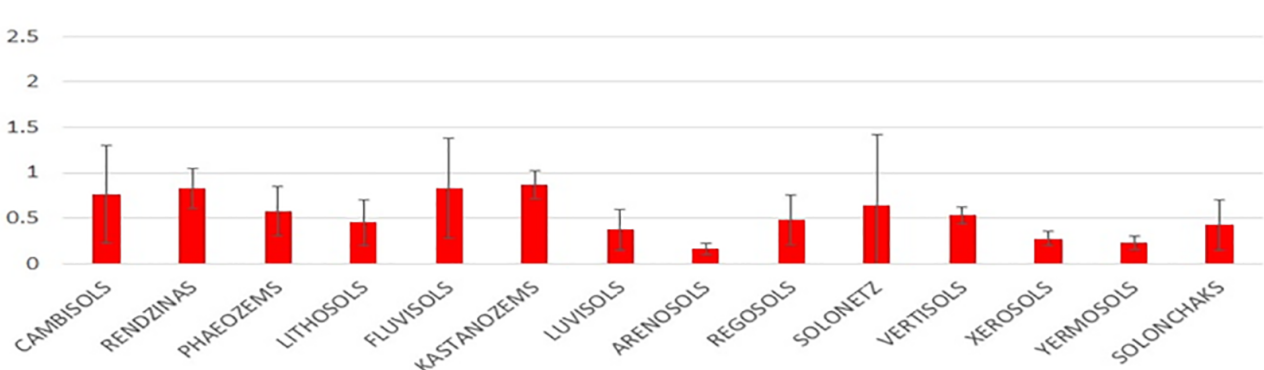

Figure 1. SOC content (\%) in topsoil and subsoil in the major soil groups of the NENA region with standard deviation related to soil class.

Table 1. Soil inorganic carbon level and the resistance to land degradation in the major soil units of the Near East North Africa region (Source: DSMW, FAO, 2007).

\begin{tabular}{lrlrr}
\hline Soil classes & $\begin{array}{r}\text { Area, } \\
1000 \mathrm{~km}^{2}\end{array}$ & $\begin{array}{l}\text { Resistance to land } \\
\text { degradation }\end{array}$ & \multicolumn{2}{c}{$\begin{array}{c}\text { Average SIC } \\
\text { content }(\%)\end{array}$} \\
\cline { 4 - 6 } & & & Topsoil & Subsoil \\
\hline Cambisols & 178.9 & High & 0.25 & 0.64 \\
Fluvisols & 232.7 & High & 1.12 & 1.40 \\
Kastanozems & 26.0 & High & 1.69 & 3.96 \\
Regosols & 1193.2 & High & 1.18 & 0.23 \\
Luvisols & 121.6 & Moderate & 0.02 & 0.11 \\
Phaeozems & 3.8 & Moderate & 0.40 & 0.70 \\
Rendzinas & 25.6 & Low & 2.80 & 4.80 \\
Lithosols & 2914.3 & Low & 0.01 & 0.06 \\
Vertisols & 45.4 & Low & 0.45 & 0.72 \\
Xerosols & 498.5 & Low & 0.25 & 0.45 \\
Yermasols (Aridisols) & 4670.6 & Low & 2.50 & 2.30 \\
Solonchaks & 230.1 & Very low & 3.60 & 3.90 \\
Solonetz & 31.2 & Very low & 0.06 & 0.36 \\
Arenosols & 384.0 & Very low & 0.00 & 0.00 \\
\hline
\end{tabular}

\section{Results and discussion}

\subsection{Land capability and SOC in the NENA region}

According to the results based on the land capability model, $40 \%-100 \%$ of soils in the region fall within the low, very low and non-arable classes (Fig. 2). Thus, the proportion of highly and medium productive soils varies between $0 \%$
(Bahrain, Qatar, Oman and UAE) and $60 \%$ (Jordan). Countries and territories like Iraq, Lebanon, Morocco, Palestine, Somalia, Syria and Tunisia have between $9 \%$ and $20 \%$ highly to medium productive soils. The remaining NENA countries and territories have less than $5 \%$ high and medium productive lands. Some of these countries and territories belong to the food-insecure nations. 


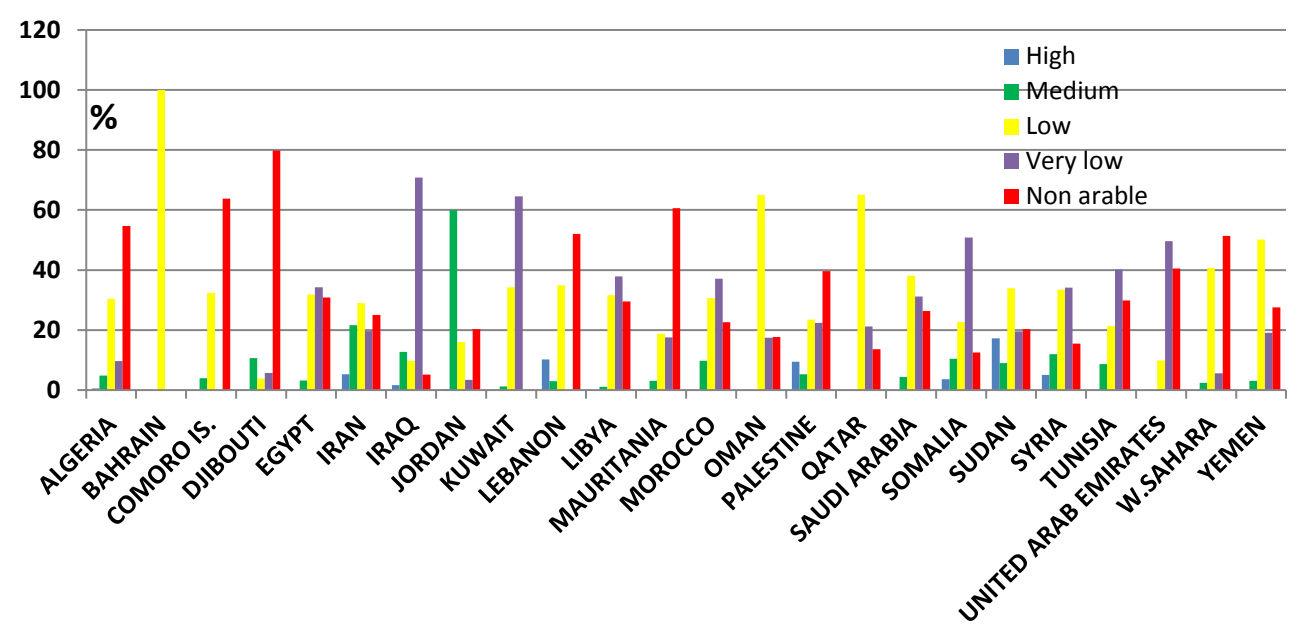

Figure 2. Distribution of land capability classes (\% of total national area) for 20 countries and territories of the NENA region, based on the USDA model (1999) and Digital Soil Map of the World (FAO, 2007).

The soil productivity concept is based strictly on soil properties. But, with the lack of water in dry lands and the prevalence of rainfed agriculture, the soil cannot show its full potential for food production. Similarly, irrigation with brackish water restricts crop productivity due to the development of secondary soil salinity. With properly managed irrigation, the medium productive lands can provide moderately good harvests. For instance, our field observation in Jordan showed that a large area of productive lands was cropped with barley, not because of land suitability, but due to low rainfall $(<200 \mathrm{~mm})$. In drought-affected years, the land is converted into a grazing area for small ruminants following crop failure to make maximal profit from the exploitation.

The low productivity of the soil is reflected in the SOC contents. The accumulation of SOC in the NENA region is limited by the high mineralization rate (Bosco et al., 2012). Climate change and recurrent drought events affect SOC sequestration in the soil. It is estimated that a rise in temperature of $3{ }^{\circ} \mathrm{C}$ would increase the emission of carbon dioxide by $8 \%$ (Sharma et al., 2012).

Among the soil properties affecting SOC, the clay and calcium carbonate contents are most relevant. High clay content tends to counteract the decomposition of SOC, as found in clay soils of Morocco and in Vertisols of northern Syria (FAO and ITPS, 2015). But, the dominant soil classes (Table 1), characterized by sandy and sandy loam textures, are subject to fast decomposition. Next to the clay texture, the presence of calcium carbonate decreased the decomposition of composted organic material in subhumid coastal Lebanon (Al Chami et al., 2016). This slower turnover of organic matter was explained by the low porosity and prevalence of micropores in soil macroaggregates (Fernãndez-Ugalde et al., 2014).

\subsection{Mapping of soil carbon stocks}

Based on the mapping of SOC density (ton ha ${ }^{-1}$ ), $69 \%$ of the regional soils have a density below 30 tons ha $^{-1}$ (Fig. 3), a value considered as a threshold for C-deficient soils (Batjes and Sombroek, 1997). This could be linked to the arid conditions prevailing in the region with flat lands and limited humid mountain areas. Consequently, the majority of the countries and territories of the NENA region have moderate to relatively low total stocks of SOC.

This is especially relevant to the Gulf countries, Iran, Tunisia and Morocco, with values below 221 Mt (Fig. 4). Such low OC sequestration potential can be explained by the sparse natural vegetation and the reliance on irrigation to produce food and feed crops. A regional implementation plan for sustainable management of NENA soils appeared in 2017 (http://www.fao.org/3/a-bl105e.pdf; last access: 8 October 2017). In fact, the total stocks in the topsoils $(0-0.3 \mathrm{~m})$ of NENA countries and territories represent only $4.1 \%$ of the world global stock (http://www.fao.org/3/a-bs049e.pdf; last access: 13 March 2018).

A comparison has been undertaken between the FAO methodology, adopted in the present work (two soil layers: $0-0.3,0.3-1 \mathrm{~m}$ ), and a previous study whereby the soil profile was divided into six depths down to $2 \mathrm{~m}$ (Hengl et al., 2014). Both approaches agree about the NENA region (SOC content: $1 \%-2 \%$ and SOC stock: 20-204 ton $\mathrm{ha}^{-1}$ ), as confirmed by the Global Soil Organic Carbon Map (http://www.fao.org/global-soil-partnership/ pillars-action/4-information-and-data/

global-soil-organic-carbon-gsoc-map/en/; last access: 13 March 2018). The global gridded soil information based on machine learning (SoilGrid250m) which contains 1.6 billion pixels also predicted SOC density, but the arid and semi-arid zones are under-measured and thus pseudo 

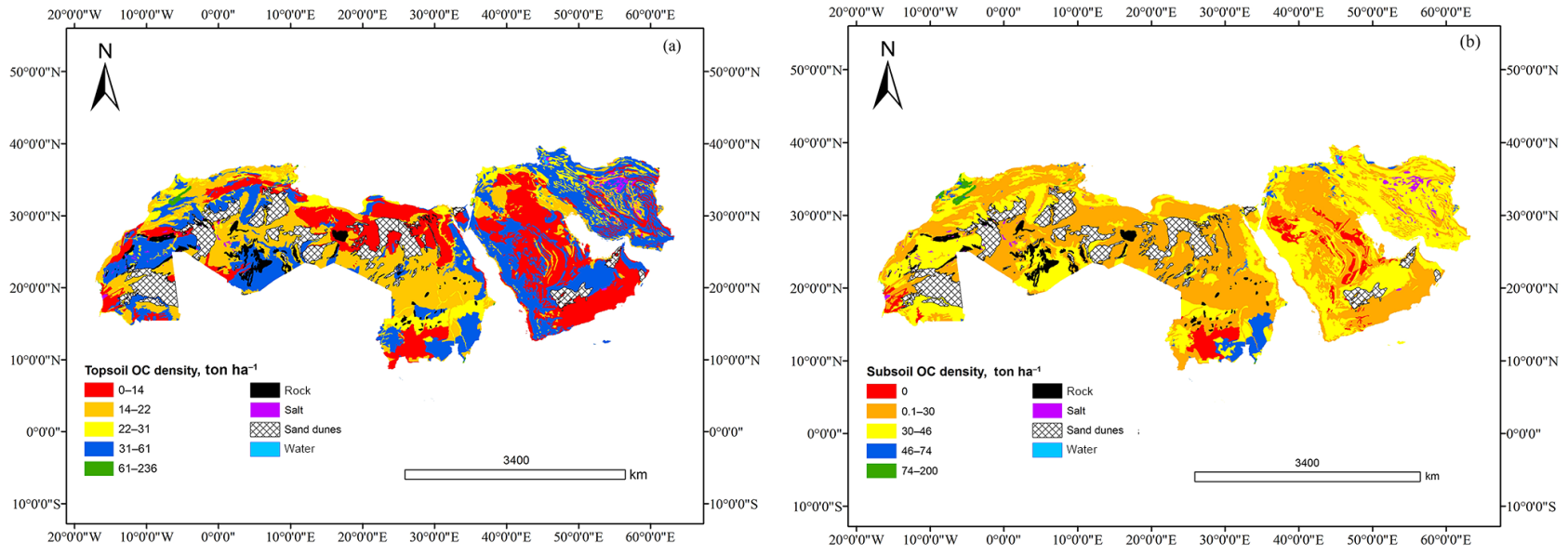

Figure 3. Spatial distribution of SOC density (ton ha ${ }^{-1}$ ) in topsoils (a) and subsoils (b) of the NENA region.
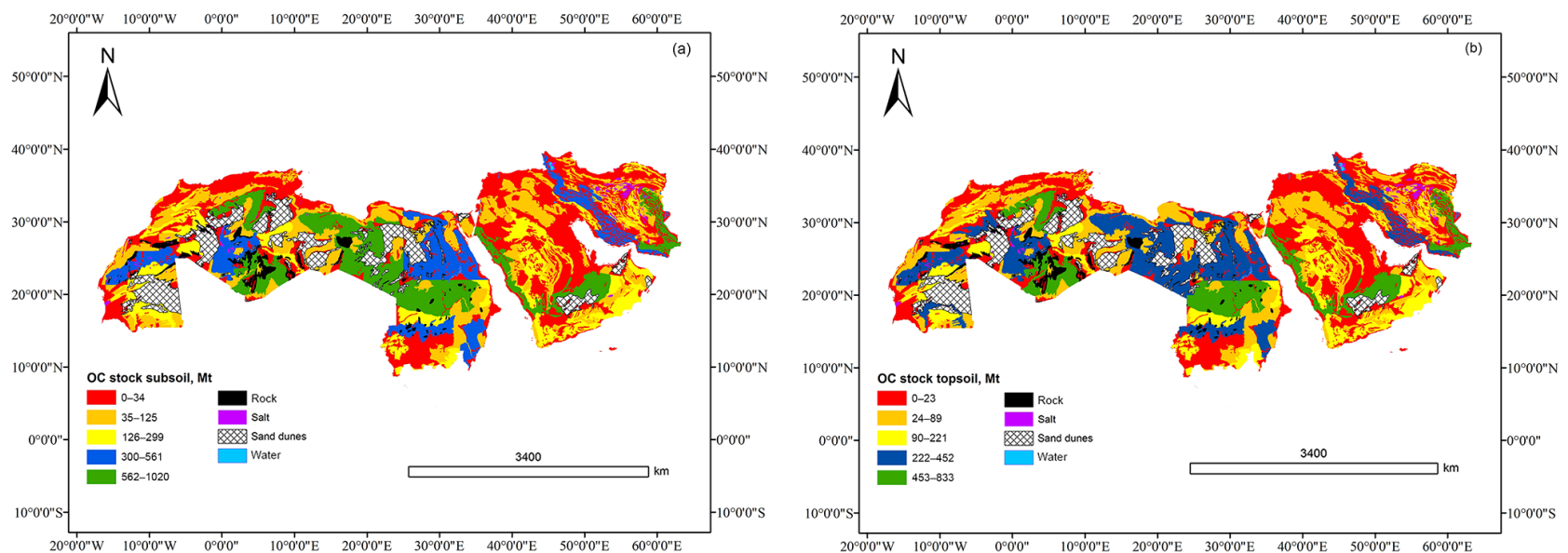

Figure 4. Spatial view of total soil organic carbon stock (Mt) across the countries and territories of the NENA region (a: topsoil; b: subsoil).

observations based on expert knowledge were introduced to predict the SOC content in the soil at seven standard soil depths (Hengl et al., 2017).

The choice of scale when using or producing soil maps may lead to uncertainty in small countries and places with fragmented land use (Darwish et al., 2009). The coarse scale adopted in this work $(1: 5000000)$ could be a source of uncertainty. Practically, this corresponds to a polygon of $0.5 \mathrm{~cm} \times 0.5 \mathrm{~cm}\left(\right.$ area $\left.<0.25 \mathrm{~cm}^{2}\right)$, the equivalent of an area of $6.25 \mathrm{~km}^{2}$ on the ground. To test this, the results of the current estimation $(1: 5000000)$ of SOC stocks in Lebanon were compared with the large-scale mapping at 1:50000 for Lebanon (Darwish et al., 2006). The FAO scale gave an overestimation of $11.2 \%$ in the topsoil, an underestimation of $16.4 \%$ in the subsoil and a $14.4 \%$ underestimation in the whole profile (Darwish and Fadel, 2017). Therefore, the level of mapping uncertainty falls within the reported diagnostic power of soil maps, with a map purity of $65 \%-70 \%$ (Finke et al., 2000). In our study, the match- ing reached $83.6 \%-88.2 \%$. Any loss of information related to small, non-mappable soil units in coarse-scale mapping $(1: 5000000$ or $1: 1000000)$ could be rectified by national and subregional large-scale soil mapping (1:50000 and 1: 20000).

Another source of error can be associated with the SOC content in soil classes or major groups from the DSMW (FAO, 2007). The level of uncertainty in the assessment of the SOC density in NENA countries and territories depends on the variability of SOC, as suggested by the standard deviations of the means (Fig. 1). Therefore, the SOC content is the major source of variability for the SOC density at the soil class level. Cambisols and Fluvisols are shown to have the largest standard deviation, caused by a long land use history and large anthropogenic impact. Subsoil is less subject to pedoturbation and direct human influence; thus SOC content has lower variability. 


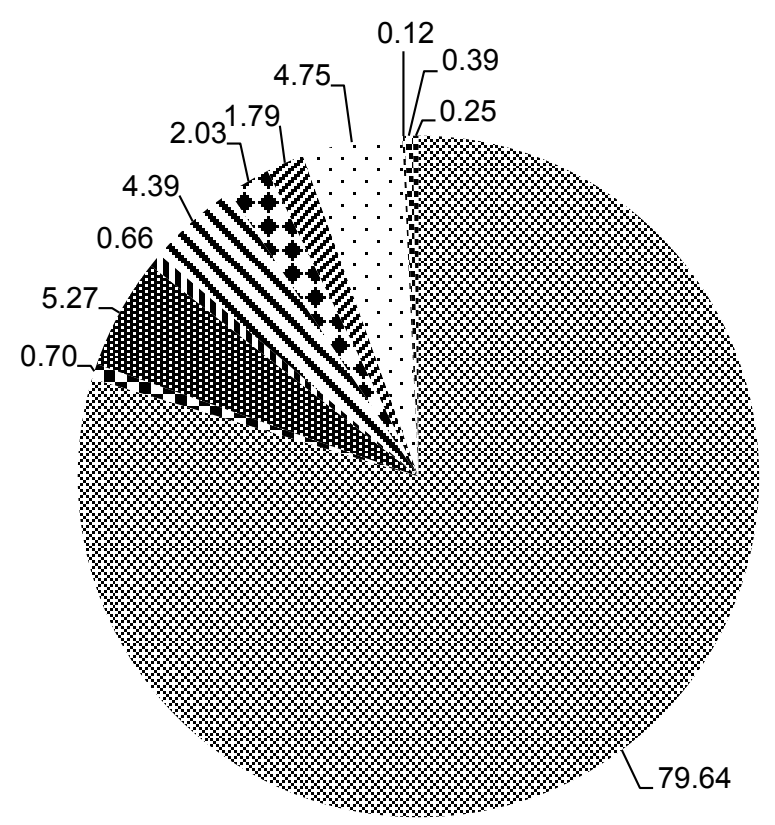

\author{
x Bare land \\ $\neg$ Broadleaved deciduous trees \\ \# Grassland \\ I Irrigated crops \\ VRainfed crops \\ - Shrub and herbaceous \\ a Shrubland \\ - Sparse vegetation cover \\ \$ Vegetation flooded saline/brackish \\ water \\ Waterbodies \\ - Others*
}

*Others: mixed trees, needle-leaved,evergreen trees and urban

Figure 5. Proportion of main land cover (\% total land area) and land use in the NENA region (http://maps.elie.ucl.ac.be/CCI/viewer/index. php; last access: 10 September 2017).

\subsection{Land cover mapping and stocks of SOC}

Based on the land cover map of the ESA, the bare lands correspond to $80 \%$ of the whole NENA region (Fig. 5). Grassland, sparse vegetation cover and rainfed agriculture represent $4.39 \%-5.27 \%$. The irrigated crops do not exceed $0.66 \%$ of the total area, distributed in a limited cultivated area (Fig. 5). The NENA region possesses a land area of about 15 million $\mathrm{km}^{2}$, with a total population exceeding 400 million inhabitants (about $6 \%$ of world population) but with only $1 \%$ of the world's renewable water resources (https://www.slideshare.net/FAOoftheUN/ plenary1-keynote-speech-16dec2013az; last access: 10 September 2017). In fact, the irrigated area corresponds to $247.5 \mathrm{~m}^{2}$ per capita. This could be one of the reasons for the high dependency on imported food, exacerbated by demographic pressure, rapid urbanization, water scarcity and climate change (FAO, 2015).

The combination of the SOC stock map with the land cover map showed a significant effect of land cover on SOC stocks in the NENA region. As can be expected, shrublands, sparse vegetation and bare lands gave the smallest values, between 14 and 26 ton ha $^{-1}$ (Fig. 6). In a mixture of shrublands and herbaceous vegetation, the SOC increases to 40 ton ha $^{-1}$. The highest density ( 30 and 60 ton ha ${ }^{-1}$ ) is found under forest stands.

Despite the expected impact of frequent plowing, the soils under mixed trees and irrigated crops have higher SOC density than rainfed crops. This could be linked to the higher biomass produced under irrigated conditions in these waterlimited areas. The highest SOC stock is observed under evergreen forests, whose area is very limited $\left(3380 \mathrm{~km}^{2}\right.$ corresponding to $0.02 \%$ of the total area). Surprisingly, the stock found under urban soils $\left(\approx 30\right.$ tons ha $\left.{ }^{-1}\right)$ is moderate. This could be related to the urban encroachment on prime soils. Between 1995 and 2015, rapid urban growth caused loss of over 53 million tons of soils, $16 \%$ of which correspond to prime soils (Darwish and Fadel, 2017). The assessment of SOC content in the NENA region showed a decline of OC content in topsoil by up to $1 \%$ between 2001 and 2009 (Stockman et al., 2015). Land cover change is considered to be the primary agent of change of SOC, followed by temperature and precipitation.

In addition to the stocks of SOC in relation to land cover-land use, the stocks of SOC and SIC were established per country/territory (Fig. 7). The range of SIC stocks is very wide, from less than 25 tons ha $^{-1}$ (Gaza subsoil) to 450 tons ha $^{-1}$ (Bahrain subsoil), while that of SOC varies between $\approx 20$ tons ha $^{-1}$ (Bahrain subsoil) and 45 tons ha $^{-1}$ (Sudan subsoil). Based on the stocks of SIC in the subsoils, the countries and territories are separated into three groups. The first (Bahrain, Oman, Egypt, Saudi Arabia, UAE and Yemen) is dominated by calcareous parent materials, with values in the subsoil exceeding 200 tons ha $^{-1}$ (Fig. 7). The second group (Kuwait, Libya, Iran, Iraq, Algeria, Qatar, Morocco and Tunisia) shows a SIC density of between 100 and 200 tons ha $^{-1}$. Finally, the third group (Gaza, 


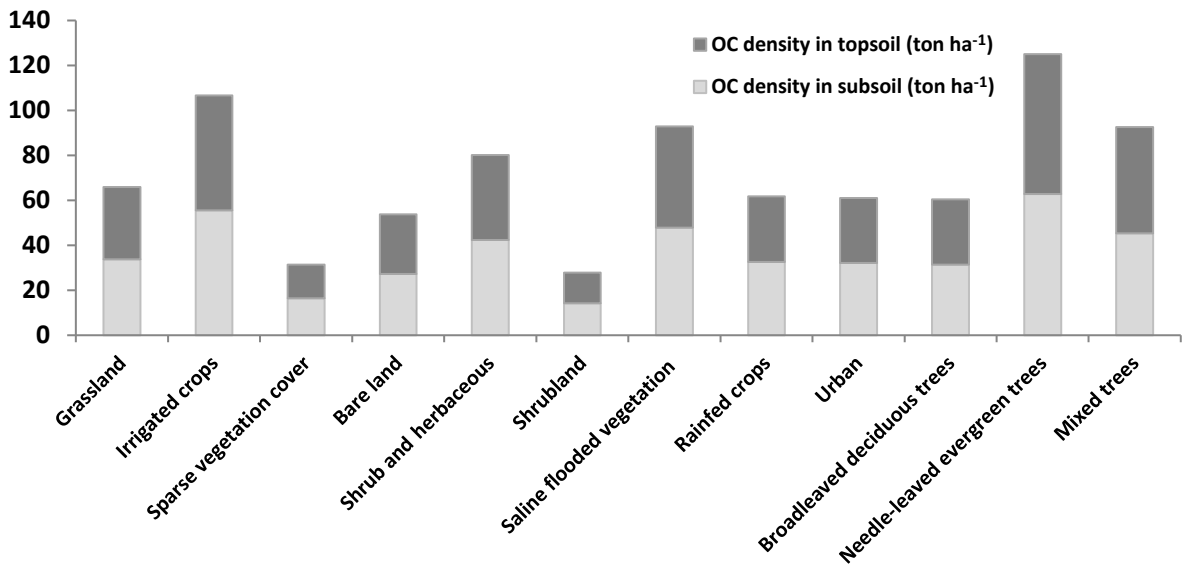

Figure 6. SOC density (tons ha $\left.{ }^{-1}\right)$ in the topsoil $(0-0.3 \mathrm{~m})$ and subsoil $(0.3-1.0 \mathrm{~m})$, calculated from the FAO DSMW (FAO, 2007), with corresponding land cover (http://maps.elie.ucl.ac.be/CCI/viewer/index.php; last access: 10 September 2017).

Jordan, Lebanon, Mauritania, Syria and Sudan) has less than 100 tons ha ${ }^{-1}$.

\subsection{Challenges of carbon sequestration in NENA agro-ecosystems}

Climatic conditions characterized by wetting-drying cycles and a long dry and hot season (Boukhoudoud et al., 2016) promote the decomposition of SOC. Further, frequent cultivation, irrigation with saline water and soil salinity rise in coastal areas exert significant effects on soil microbial functional properties. For instance, 3 months after the application of glyphosate-based herbicide to the soil under olive trees in coastal Lebanon, lipase activities significantly decreased (Boukhoudoud et al., 2017). Soil classification and SOC mapping help to identify hotspots that need to be improved or require special management measures and bright spots with satisfactory $\mathrm{C}$ accumulation levels that need to be protected. In this section, major practices affecting SOC will be presented, followed by a discussion of preventive and remediation measures.

\subsubsection{Tillage and SOC}

Tillage practices contribute to the vulnerability of soils to water erosion. If not properly managed, some 41 million hectares in the NENA region would be affected by water erosion (FAO and ITPS, 2015). The erosion of soil surface layers can affect the soil carbon in two possible ways. The greater exposure of carbonates to climatic elements could increase the loss of SIC to the atmosphere and ground water. Compared to stable soils, the higher decomposition of SOC in eroded soils decreases the productivity of cultivated crops and can reduce SOC stock, if not properly managed (PlazaBonilla et al., 2015).

A possible measure to reduce the risk of erosion is notillage practice. No-tillage coupled with mulching, to reduce weed development and omit herbicide application, as part of conservation agriculture (CA), aims to return more plant residues to the soil, enhance $\mathrm{C}$ sequestration, increase soil aggregates, improve water infiltration and protect soil carbon from decomposers (Palm et al., 2014). Through a modification of common practices, such as the frequency and depth of tillage, changes in the SOC could be promoted in most soils. Experiments conducted by ICARDA, Syria, showed that notillage performed well in terms of energy and soil conservation (Plaza-Bonilla et al., 2015). Elsewhere, in Palestine, soil conservation was found to pay, with a net profit 3.5 to 6 times higher than without conservation measures (FAO and ITPS, 2015). In dry land regions, agricultural activities based on CA practices are beneficial as crop residues are left on the soil surface (Plaza-Bonilla et al., 2015). The presence of residues protects the soils from high evaporation, water and wind erosion. This is especially relevant to soils that are sensitive to degradation, such as the very shallow Lithosols, the periodically swelling and shrinking Vertisols, Gypsic Yermasols (Aridisols), the poorly structured Solonchaks and Solonetz, the sandy-textured Arenosols and the desert soils (Xerosols).

Major constraints facing soil conservation measures, in the eastern Mediterranean, were due to knowledge and perception, prevailing practices of complete removal such as hay or forage and sometimes burning of residues after harvest, land tenure and the type of landscape (FAO, 2012; FAO and ITPS, 2015). These factors are socioeconomic in nature, rather than scientific. They are related to the ability of growers to accept new techniques and adopt them. In many situations, the transfer from the research stations to the farmers was not smooth. For instance, CA was successfully tested in experimental stations in Morocco and Lebanon, but several social and technical barriers prevented it from reaching farmers (Mrabet et al., 2012; FAO, 2012). 

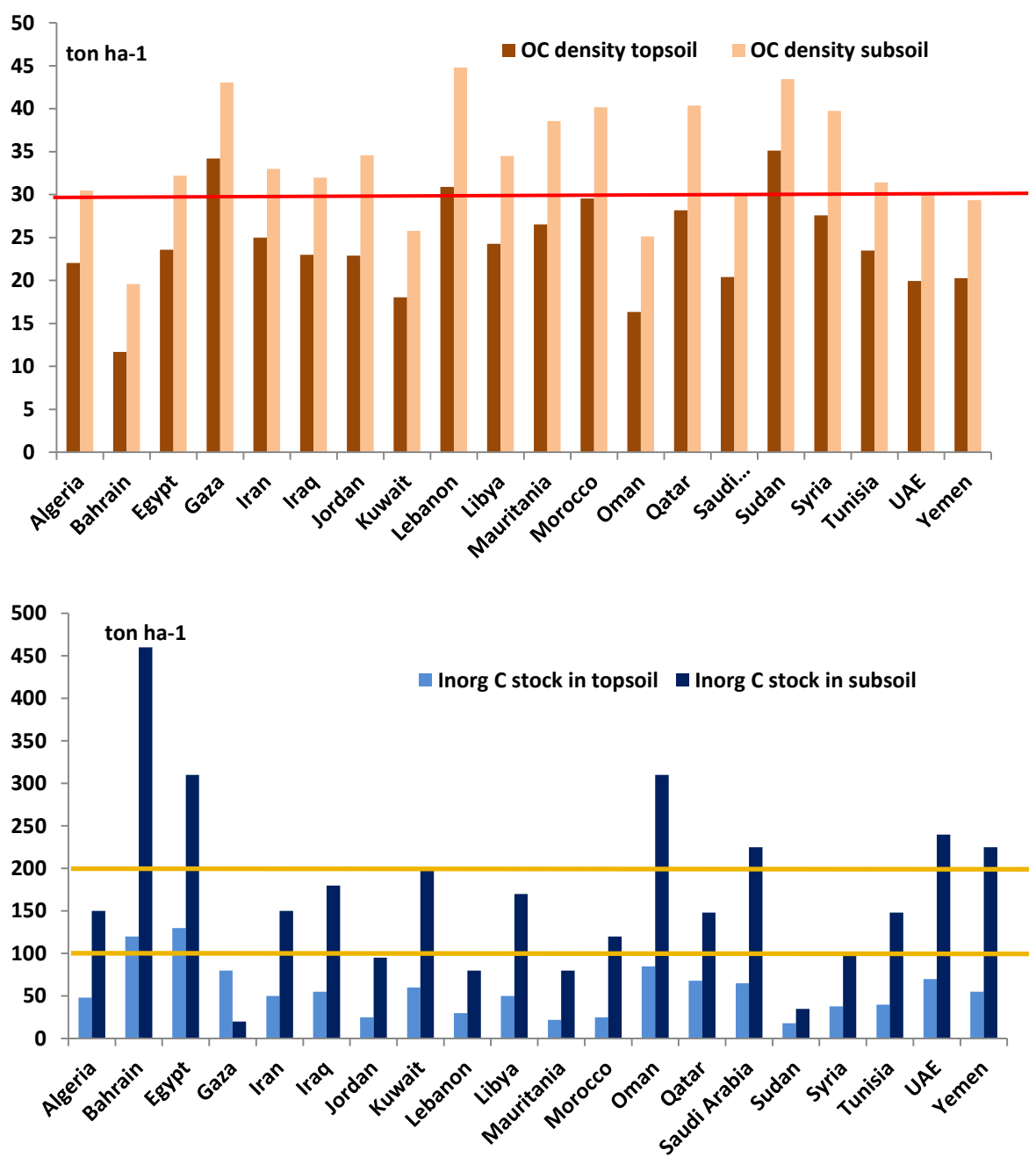

Figure 7. Soil organic carbon and soil inorganic carbon density (tons ha $\left.{ }^{-1}\right)$ in the topsoil $(0-0.3 \mathrm{~m})$ and subsoil $(0.3-1.0 \mathrm{~m})$ of the 20 countries and territories in the NENA region. The red line represents the threshold for organic carbon, and the yellow lines correspond to the limits of classes for inorganic carbon.

A debate has been taking place about the effect of notillage on SOC. Many authors agree that under CA, SOC increases near the soil surface, but not necessarily throughout the profile. A study compared 100 pairs, where no-tillage has been practiced for over 5 years. The absence of tillage led to higher $\mathrm{C}$ stocks $(0-0.3 \mathrm{~m}$ soil depth) in $54 \%$ of pairs, while $39 \%$ showed no difference in stocks (Palm et al., 2014). In the absence of tillage, the slower decomposition of residues results in higher $\mathrm{C}$ accumulation on the soil surface. Over a period of 5 years, zero tillage promoted an increase in SOC equal to $1.38 \mathrm{Mg} \mathrm{ha}^{-1}$ as compared to conventional tillage in northern Syria (Sommer et al., 2014).

\subsubsection{Agricultural practices and SOC}

Practices such as the application of $\mathrm{N}$ fertilizers, organic amendments, incorporation of residues and crop rotations influence the levels of SOC. In soil mining practices with- out minimal input of fertilizers, the lack of available nutrients makes most crops entirely reliant on the mineralization of accumulated SOC (Plaza-Bonilla et al., 2015). In East Africa, 14 years of continuous cultivation without any input decreased SOC from $2 \%$ to $1 \%$ (Sharma et al., 2012). The application of $\mathrm{N}$ fertilizers was associated with increased levels of soil $\mathrm{C}$, as compared to the absence of $\mathrm{N}$ fertilizers (Palm et al., 2014). In a 10-year rotation of wheat-grain legume in northern Syria, the application of $\mathrm{N}$ fertilizers to the cereal caused a notable increase of SOC in the top $1 \mathrm{~m}$ of soil, equal to $0.29 \mathrm{Mg} \mathrm{ha}^{-1} \mathrm{yr}^{-1}$ (Sommer et al., 2014). Similarly, in the semi-arid Lebanese area (Anti-Lebanon mountains), legumes (Vicia sp., Lathyrus sp.) intercropped with barley (Hordeum vulgaris) significantly increased SOC in cherry orchards (Darwish et al., 2012). Roots of cover crops contributed some 140 and $250 \mathrm{~kg} \mathrm{ha}^{-1}$ season $^{-1}$ of organic 
matter (OM) against $95-665.7 \mathrm{~kg} \mathrm{ha}^{-1}$ season $^{-1}$ of OM for the aboveground parts.

The effects of crop rotations on SOC are related to the amounts of above and belowground biomass produced and retained in the system. In a study conducted in semi-arid northern Syria, a 12-year rotation produced higher SOC in wheat-medic (12.5 $\mathrm{g} \mathrm{SOC} \mathrm{kg}^{-1}$ soil) and wheat-vetch (13.8 $\mathrm{g} \mathrm{SOC} \mathrm{kg}^{-1}$ soil) rotations, as compared to continuous wheat $\left(10.9 \mathrm{~g} \mathrm{SOC} \mathrm{kg}^{-1}\right.$ soil) or wheat-fallow (Masri and Ryan, 2006). In this rainfed system, the introduction of a forage legume (vetch/medic) with wheat, over a decade, was able to significantly raise the level of SOC. Further, the combination of crop rotations and no-tillage was found to sequester more $\mathrm{C}$ than monocultures (Palm et al., 2014). One means of building up biomass is through winter cover crops. Their beneficial impact on $\mathrm{C}$ sequestration and water infiltration has been demonstrated. The presence of a cover crop on the soil surface protects the soil against erosion. Still, more research is needed about the best species to be used, the optimum termination strategies of the cover crop as well as the best date and density of planting and best management practices of consequent crops (Plaza-Bonilla et al., 2015). The choice of cover crops in the NENA region is crucial as these can compete with the main crop for the limited water resources.

In poor dry land regions, especially in the rainfed agricultural systems, some practices hinder the accumulation of SOC. Overall, crop residues serve as fodder or are used for household cooking or heating, leaving little plant material on the soil surface. Even animal dung is used as cooking fuel in many regions. The low SOC content could be improved by increasing the crop residues produced and incorporated. Such an approach requires the application of fertilizers in order to avoid the depletion of soil nutrients (Plaza-Bonilla et al., 2015). By removing residues, animal dung and crops, no residues are left in the soil except roots. In the absence of fertilizers, these practices can mine the soil $\mathrm{N}$, and over the years the pool of nutrients in the soil can be imbalanced and depleted.

Some authors question the validity of remediation measures to promote SOC accumulation in most of the NENA region. Results from research stations in Egypt and Syria provide evidence to the contrary. In a trial in northeast Cairo, Egypt, the irrigation of a sandy soil with sewage water, for 40 years, changed its texture to loamy sand (Abd el-Naim et al., 1987). This modification of the soil texture led to a significant improvement of the soil physical properties. Further, within the same long-term trial, the irrigation with sewage water, for 47 years, increased SOC to $2.79 \%$, against $0.26 \%$ in the control experiment (Pescod and Arar, 2013). This rather slow accumulation could be related to the sandy soil texture and to the input of the organic matter in labile, soluble forms.

The addition of more stable composted materials was tested in semi-arid north Syria. The amount of compost,
$10 \mathrm{Mg} \mathrm{ha}^{-1}$ every 2 years, needed to raise the SOC, was too large in these rainfed systems. This amount is larger than the compost available in these conditions. Rather than relying on compost, the authors found that a combination of reduced tillage and a partial retention of crop residues moderately increased SOC (Sommer et al., 2014). The quality of residues seems to affect the SOC in the short term, but in the medium term, it is the quantity that matters (Palm et al., 2014).

\subsubsection{Impact of irrigation on agricultural soils}

The irrigated land represents a minor fraction of agriculture in the NENA region, but irrigated crops are essentially found on prime soils (Fig. 4). Frequent wetting of irrigated soils makes them more likely to lose $\mathrm{C}$ as compared to dry soils. But, this partial loss is compensated by higher biomass production and greater OM inputs from roots, even if residues are removed. Lack of moisture limits soil mineralization (Sharma et al., 2012). Irrigated soils promote intense microbial activity and a rapid decomposition of SOC. In the fertile region of Doukkala, Morocco, known for producing wheat and sugar beet, a decade of irrigated farming decreased soil organic matter by $0.09 \%$ per year (FAO and ITPS, 2015). This loss could have been reduced through the incorporation of crop residues. But, in these mixed farming systems, aboveground residues are consumed by farm animals.

The irrigation of soils in the NENA region is expected to affect the SIC. Dry land soils were considered to contain an equivalent stock of SIC to SOC (Sharma et al., 2012). But higher SIC than SOC levels were found in this study, notably in the subsoils. Despite this large stock, there is a major knowledge gap regarding the effects of land use and management on the dynamics of SIC. This is especially relevant to the irrigation with calcium- or sodium-enriched groundwater (Plaza-Bonilla et al., 2015). In these conditions, the formation of calcium carbonate could be accompanied by some release of carbon dioxide while the development of sodicity can cause irreversible SOC loss.

\section{Conclusions}

The NENA area, consisting of $14 \%$ of the Earth surface, contributes only $4.1 \%$ of total SOC stocks in topsoil. The soil resources of the NENA region are developed under dry conditions with prevailing rainfed agriculture. The majority of lands in NENA countries and territories are of low productivity. The current mapping of SOC density showed that $69 \%$ of soil resources represent a SOC stock below 30 tons ha ${ }^{-1}$, indicating that the soils of the NENA region are not enriched with OC. Highest stocks $\left(60\right.$ tons ha ${ }^{-1}$ ) were found in forests, irrigated crops, mixed orchards and saline flooded vegetation. This means that SOC can be increased in the soils of the NENA region under appropriate and sustainable soil management practices. The moderate density $\left(\approx 30\right.$ tons $\left.^{-1}\right)$ in urban areas indicates land occupied by 
urban growth and expansion on prime lands. The stocks of SIC were higher than SOC density, due to the calcareous nature of soils. In subsoil, the SIC stock ranged between 25 and 450 tons ha $^{-1}$, against $20-45$ tons ha ${ }^{-1}$ for SOC. The OC sequestration in the NENA region is a possible task to mitigate climate change and sustain food security despite the hostile climatic conditions and poor land stewardship and governance. Practices of conservation agriculture (no-tillage, intercropping and agropastoral system, winter cover crops, proper rotation) could be effective in reducing evaporation and water and wind erosion and in promoting aboveground and belowground biomass production. Land cover and land use affected the amounts of SOC retained in the soil ecosystem. A good result was achieved in Lebanon through winter cover crop consisting of a fruit trees-legume-barley intercropping system. Knowledge gaps exist with respect to the effect of irrigation on SOC and SIC. Constraints facing soil conservation measures and carbon sequestration in the NENA region can be faced with awareness raising and capacity building at the level of stakeholders and decision makers. Sustainable soil management can contribute to the alleviation of the pressure on soil resources, improvement of SOC sequestration and maintenance of soil resistance to degradation.

Data availability. The digital soil map of the world (DSMW) Version 3.6, completed January 2003 and updated 2007 can be downloaded from FAO, 2017: (http://www.fao.org/geonetwork/srv/en/metadata.show?id=14116; last access: 20 December 2017. The 2015 Land Cover map of the NENA countries and territories can be downloaded from the global LC at $300 \mathrm{~m}$ spatial resolution (http://maps. elie.ucl.ac.be/CCI/viewer/index.php; last access: 10 September 2017). The Global Soil Organic Carbon Map can be accessed from (http://www.fao.org/global-soil-partnership/pillars-action/ 4-information-and-data/global-soil-organic-carbon-gsoc-map/en/; last access: 13 March 2018) and the SOC stock in topsoil can be downloaded from (http://www.fao.org/3/a-i8195e.pdf; last access: 19 August 2018). The regional implementation plan for sustainable management of NENA soils appeared in 2017 (http://www.fao.org/3/a-bl105e.pdf; last access: 8 October 2017). The Voluntary Guidelines for Sustainable Soil Management can be accessed from http://www.fao.org/3/a-bl813e.pdf; last access: 17 November 2017.

Author contributions. TD provided the idea and contributed to the concept note, production and analysis of SOC data in NENA countries and territories. AF produced the land cover and SOC maps of the area of study. TA provided the main part of the challenges of the conservation agriculture and edited the paper.

Competing interests. The authors declare that they have no conflict of interest.
Special issue statement. This article is part of the special issue "Regional perspectives and challenges of soil organic carbon management and monitoring - a special issue from the Global Symposium on Soil Organic Carbon 2017'. It is a result of the Global Symposium on Soil Organic Carbon, Rome, Italy, 21-23 March 2017.

Acknowledgements. This paper was supported by the FAO, GSP-ITPS, UNESCWA and CNRS Lebanon within a land degradation assessment and SOC mapping project related to food security.

Edited by: Annette Cowie

Reviewed by: two anonymous referees

\section{References}

Abd Elnaim, E. M., Omran, M. S., Waly, T. M., and El Nashar, B. M. B.: Effects of prolonged sewage irrigation on some physical properties of sandy soil, Biol. Waste., 22, 269-274, 1987.

Al Chami, Z., Bou Zein Eldeen, S., Al Bitar, L., and Atallah, T.: Decomposition of olive-mill waste compost, goat manure and Medicago sativa in Lebanese soils as measured using the litterbag technique, Soil Res., 54, 191-199, 2016.

Atallah, T. Jamous, C. Debs, P., and Darwish, T.: Biosolid recycling to enhance carbon sequestration in mountainous Lebanese conditions, Leb. Sci. J., 13, 69-79, 2012.

Batjes, N. H. and Sombroek, W. G.: Posibilities for carbon sequestration in tropical and subtropical soils, Glob. Change Biol., 3, 161-173, 1997.

Bosco, S., Di Bene, C., and Bonari, E.: The effect of crop management on soil organic matter in the carbon footprint of agricultural products, 8th Int. Conf. on Life Cycle assessment in the agri-food sector, Saint-Malo, France, 1-4 October 2012.

Boukhoudoud, N., Gros, R., Darwish, T., and Farnet Da Silva, A. M.: Agriculture practice and coastal constraint effects on microbial functional properties of soil in Mediterranean olive orchards, Europ. J. Soil Sc., 67, 470-477, https://doi.org/10.1111/ejss.1234, 2016.

Boukhoudoud, N., Farnet Da Silva, A. M., Darwish, T., and Gros, R.: Olive mill waste and glyphosate-based herbicide addition to olive grove soils: effects on microbial activities and their responses to drying/rewetting cycles, Soil Use Manage, 33, 499510, https://doi.org/10.1111/sum.12367, 2017.

Cerdà, A., Gonzalez Penaloza, F., Santin, C., and Doerr, S. H.: Land abandonment, fire recurrence and soil carbon content in the Macizo del Caroig, Eastern Spain, Geophys. Res., Abstracts 14, EGU2012-14331, 2012.

Darwish, T. and Fadel, A.: Mapping of Soil Organic Carbon Stock in the Arab Countries to Mitigate Land Degradation, Arab J. Geosci., 10, 474, https://doi.org/10.1007/s12517-017-3267-7, 2017.

Darwish, T., Khawlie, M., Jomaa, I., Abou Daher, M., Awad, M., Masri, T., Shaban, A., Faour, Gh., Bou Kheir, R., Abdallah, C., and Haddad, T. (Eds.): Soil Map of Lebanon 1/50000, Publications CNRS-Lebanon, Monograph Series 4, 1-367, 2006.

Darwish, T., Abou Daher, M., Jomaa, I., and Atallah, T.: Soil organic carbon stock estimation in Lebanese territories. 10th Inter- 
national Meeting on Soils with Mediterranean Type of Climate, CNRS-Lebanon, Book of Extended Abstracts, 113-118, 2009.

Darwish, T. M., Jomaa, I., Atallah, T., Hajj, S., Shaban, A., Zougheib, R., and Sibai Ouayda, F.: An agropastoral system as a practice to enhance organic matter in Lebanese inland mountainous soils, Leb. Sci. J., 13, 1-14, 2012.

Elhadi, M. Y.: Postharvest technology of food crops in the Near East and North Africa (NENA) region, in: Crops: Growth, Quality and Biotechnology, 643-664, WFL Publisher, Meri-Rastilan tie 3 C, 00980 Helsinki, Finland, 2005.

FAO: Country Study on Status of Land Tenure, Planning and Management in Oriental Near East Countries Case of Lebanon, FAO, RNE, SNO, Cairo, Egypt, 161 pp., 2012.

FAO: Regional Overview of Food Insecurity - Near East and North Africa: Strengthening Regional Collaboration to Build Resilience for Food Security and Nutrition, Cairo, Egypt, FAO, 2015.

FAO: The digital soil map of the world. Food and Agriculture Organization of the United Nations, Version 3.6, completed January 2003 and updated 2007 (http://www.fao.org/geonetwork/srv/en/ metadata.show?id=14116; last access: 20 December 2017.

FAO: Voluntary Guidelines for Sustainable Soil Management, Food and Agriculture Organization of the United Nations Rome, Italy, http://www.fao.org/3/a-bl813e.pdf; last access: 17 November 2017.

FAO: Digital Soil Map of the World, Version $3.6 \mathrm{http} / / /$ www.fao.org/geonetwork/srv/en/metadata.show?id=14116, last access: 23 September 2018.

FAO and ITPS: Status of the World's Soil Resources (SWSR) Main Report, Food and Agriculture Organization of the United Nations and Intergovernmental Technical Panel on Soils, Rome, Italy, 2015, htt://www.fao.org/3/a-i5199e.pdf (last access: 13 December 2017), 2015.

Fernandez-Ugalde, O., Virto, I., Barre, P., Apesteguia, M., Enrique, A., Imaz, M. J., and Bescansa, P.: Mechanisms of macroaggregate stabilisation by carbonates: implications for organic matter protection in semi-arid calcareous soils, Soil Res., 52, 180-192, 2014.

Finke, P., Hartwich, R., Dudal, R., Ibanez, J., Jamagne, M., King, D., Montanarella, L., and Yassoglou, N.: Georeferenced Soil Database for Europe, Manual of Procedures, Version 1.1. European Soil Bureau, 2000.

Guo, L. J., Lin, S., Liu, T. Q., Cao, C. G., and Li, C. F.: Effects of conservation tillage on topsoil microbial metabolic characteristics and organic carbon within aggregates under a rice (Oryza sativa L.)-wheat (Triticum aestivum L.) cropping system in Central China, PLoS One, 5, e0146145, https://doi.org/10.1371/journal.pone.0146145, 2016.

Hengl, T., de Jesus, J. M., MacMillan, R. A., Batjes, N. H., Heuvelink, G. B M., Ribeiro, E., Rosa, A. S., Kempen, B., Leenaars, J. G. B., Walsh, M. G., and Gonzalez, M. R.: SoilGrids1km-Global Soil Information Based on Automated Mapping, PLoS ONE, 9, e105992, https://doi.org/10.1371/journal.pone.0105992, 2014.
Hengl, T., Mendes de Jesus, J., Heuvelink, G. B. M., Ruiperez Gonzalez, M., Kilibarda, M., Blagotić, A., Shangguan,W., Wright, M. N., Geng,, X., Bauer-Marschallinger, B., Guevara, M. A., Vargas, R., MacMillan, R. A., Batjes, N. H., Leenaars, J. G. B., Ribeiro, E., Wheeler, I., Mantel, S., and Kempen, B: SoilGrids250m: Global gridded soil information based on machine learning, PLoS ONE, 12, e0169748, https://doi.org/10.1371/journal.pone.0169748, 2017.

Lal, R.: Soil erosion and the global carbon budget, Env. Int., 29, 437-450, 2003.

Masri, Z. and Ryan, J.: Soil organic matter and related physical properties in a Mediterranean wheat-based rotation trial, Soil Till. Res., 87, 146-154, 2006.

Mrabet, R., Moussadek, R., Fadlaoui, A., and van Ranst, E.: Conservation agriculture in dry areas of Morocco, Field Crops Res., 132, 84-94, 2012.

Palm, Ch., Blanco-Canqui, H., DeClerck, F., Gatere, L., and Grace, P: Conservation agriculture and ecosystem services: An overview. Agriculture, Ecosys. Environ., 187, 87-105, https://doi.org/10.1016/j.agee.2013.10.010, 2014.

Pescod, M. B. and Arar, A.: Treatment and use of sewage effluent for irrigation, Butterworths, https://books.google.com.lb/books (last access: 30 Juli 2018), ISBN: 1483162257, 211-212, 2013.

Plaza-Bonilla, D., Arrúe, J. L., Cantero-Martínez, C., Fanlo, R., Iglesias, A., and Álvaro-Fuentes, J.: Carbon management in dryland agricultural systems, A review, Agron. Sustain. Develop., 35, 1319-1334, 2015.

Sharma, P., Abrol, V., Abrol, S., and Kumar, R.: Climate change and carbon sequestration in dryland soils, in: Tech open access book, chap. 6, 26 pp., https://doi.org/10.5772/52103 (last access: 31 July 2018), 2012.

Sommer, R., Piggin, C., Feindel, D., Ansar, M., van Delden, L., Shimonaka, K., Abdalla, J., Douba, O., Estefan, G., Haddad, A., Haj-Abdo, R., Hajdibo, A., Hayek, P., Khalil, Y., Khoder, A., and Ryan, J.: Effects of zero tillage and residue retention on soil quality in the Mediterranean region of northern Syria, Open J. Soil Sci., 4, 109-125, https://doi.org/10.4236/ojss.2014.43015, 2014.

Stockmann, U., Padarian, J., McBratney, A., Minasny, B., deBrogniez, D., Montanarella, L., Young Hong, S., Rawlins, B. G., and Damien, J.: Global soil organic carbon assessment, Glob. Food Secur., 6, 9-16, 2015.

USDA: Land capability classification, NRCS-USDA, available at: https://www.nrcs.usda.gov/wps/portal/nrcs/detail/national/ technical/nra/?cid=nrcs143_014040 (last access: 1 March 2018), 1999.

von Grebmer, K., Bernstein, J., Hossain, N., Brown, T., Prasai, N., Yohannes, Y., Patterson, F., Sonntag, A., Zimmermann, S. M., Towey, O., and Foley, C.: Global Hunger Index: The Inequalities of Hunger, Washington, DC, International Food Policy Research Institute, Bonn, Welthungerhilfe, and Dublin, Concern Worldwide, 2017. 